\title{
Rechtsbescherming
}

\section{Het Hof van Justitie in Kamino-Datema: horen in bezwaar onder voorwaarden gesanctioneerd}

\author{
Mr. A.W.G.J. Buijze*
}

Met zijn uitspraak van 3 juli 2014 verduidelijkt het Hof van Justitie de betekenis van de rechten van de verdediging voor het Nederlandse bestuursrecht, meer in het bijzonder voor het douanerecht. Voor de douane lijkt de uitkomst positief: het horen van belanghebbenden tijdens de bezwaarprocedure is onder voorwaarden voldoende om aan de rechten van de verdediging tegemoet te komen. Afdeling 4.1.2 van de Awb blijft nog even in het beklaagdenbankje: de ruime uitzondering op de hoorplicht uit artikel 4:12 Awb lijkt niet altijd houdbaar en het Hof van Justitie wijst de rechtvaardiging van de Nederlandse regering expliciet af.

Hvf EU 3 juli 2014, gevoegde zaken C-129/13, Kamino en C-130/13 Datema, ECLI:EU:C:2014:2041

\section{De verwijzingsuitspraak van de Hoge Raad}

De feiten zijn relatief eenvoudig. Zowel Kamino als Datema is expediteur. Zij doen namens een andere onderneming aangifte van de invoer van tuinpaviljoens onder post 66011000 , 'tuinparasols en dergelijke artikelen'. De douane is het niet eens met deze classificering en vindt dat de tuinpaviljoens onder post 63069900 , 'tenten en kampeerartikelen' moeten worden gebracht. Over die laatste categorie is een anmerkelijk hoger douanerecht verschuldigd: $12,2 \%$ in plaats van $4,7 \%$. Datema en Kamino krijgen dan ook een uitnodiging tot betaling (UTB) uitgereikt voor de méér verschuldigde douanerechten. Zij worden voorafgaand aan die uitreiking niet gehoord. Dat hoeft naar Nederlands recht ook niet. De Awb noch het Communautair Douanewetboek

Mr. A.W.G.J. (Anoeska) Buijze is postdoctoraal onderzoeker bij het Utrecht Centre for Regulation and Enforcement in Europe en het Utrecht Centre for Water, Oceans and Sustainbility Law. (hierna: Douanewetboek of CDW) bevat een verplichting een douaneschuldenaar in de gelegenheid te stellen zijn standpunt kenbaar te maken over de elementen waar een navordering op is gebaseerd voordat wordt overgegaan tot de in artikel 221 lid 1 van het Douanewetboek bedoelde mededeling van een douaneschuld. Artikel 4:8 Awb is niet van toepassing, omdat het gaat om een beschikking die strekt tot het vaststellen van een financiële verplichting waartegen bezwaar kan worden gemaakt, en waarvan de nadelige gevolgen na bezwaar volledig ongedaan kunnen worden gemaakt, als bedoeld in artikel 4:12 lid $1 \mathrm{Awb}$. De verenigbaarheid van die uitzondering met het Europese recht staat echter ter discussie sinds het Hof van Justitie in 2008 het Sopropéarrest wees. ${ }^{1}$ In dit arrest oordeelde het Hof van Justitie dat de rechten van de verdediging, inclusief het recht gehoord te worden alvorens een belastende beschikking wordt genomen, ook van toepassing is in douanezaken. Dat een en ander niet is vastgelegd in het Douanewetboek doet daar niet aan af. De expediteurs stellen dan ook dat de omstandigheid dat zij niet zijn gehoord een schending is van het Unierechtelijke beginsel van eerbiediging van de rechten van de verdediging, en dat de UTB's vernietigd moeten worden.

De Hoge Raad ziet hierin anleiding om een antal prejudiciële vragen voor te leggen aan het Hof van Justitie. ${ }^{2}$ (1) Leent het Europeesrechtelijke beginsel van eerbiediging door de administratie van de rechten van de verdediging zich voor rechtstreekse toepassing door de nationale rechter?

(2a) Zo ja, moet het Europeesrechtelijke beginsel van eerbiediging door de administratie van de rechten van de verdediging aldus worden geïnterpreteerd dat het beginsel is geschonden indien de adressaat van een voorgenomen beslissing weliswaar niet is gehoord voordat de

1. HvJ EG 18 december 2008, zaak C-349/07, Sopropé, ECLI:EU:C: 2008:746, $A B$ 2009, 29, m.nt. Widdershoven.

2. HR 22 februari 2013, ECLI:NL:HR:2013:BR0666 en HR 22 februari 2013, ECLI:NL:HR:2013:BR0671. 
administratie jegens hem een bezwarende maatregel nam maar in een nadien volgende bestuurlijke (bezwaar)fase, die voorafgaat aan een rechtsingang bij de nationale rechter, alsnog in de gelegenheid is gesteld te worden gehoord?

(2b) Worden de rechtsgevolgen van schending door de administratie van het Europeesrechtelijke beginsel van eerbiediging van de rechten van de verdediging, indien zich dat inderdaad leent voor rechtstreekse toepassing, bepaald door het nationale recht?

(3) Indien de rechtsgevolgen van schending van het Europeesrechtelijke beginsel van rechten van de verdediging niet worden bepaald door het nationale recht, welke omstandigheden kan de nationale rechter bij het bepalen van de rechtsgevolgen in aanmerking nemen, en met name kan hij in aanmerking nemen of aannemelijk is geworden dat de procedure zonder de schending door de administratie van het Europeesrechtelijke beginsel van eerbiediging van de rechten van de verdediging een andere afloop zou hebben gehad?

\section{De uitspraak van het Hof van Justitie}

Het Hof van Justitie is kort over de eerste vraag, of het beginsel van eerbiediging van de rechten van de verdediging zich leent voor rechtstreekse toepassing. Het herhaalt dat de hoorplicht rust op administratieve overheden van de lidstaten wanneer zij bezwarende besluiten nemen die binnen de werkingssfeer van het Unierecht vallen, ook als de toepasselijke regeling niet uitdrukkelijk voorziet in een dergelijke formaliteit. ${ }^{3}$ In het arrest Sopropé oordeelde het Hof van Justitie al dat de nationale rechter zich ervan dient te vergewissen dat de termijn die wordt geboden voor het indienen van opmerkingen door de belanghebbende hem daadwerkelijk de mogelijkheid geeft om de rechten van verdediging uit te oefenen. Daaruit volgt, zo oordeelt het Hof van Justitie, dat belanghebbenden zich voor de nationale rechter op de eerbiediging van de rechten van de verdediging moeten kunnen beroepen. ${ }^{4}$ De advocaat-generaal voert ter ondersteuning van die conclusie aan dat wanneer administratieve autoriteiten wel gehouden zijn de rechten van de verdediging te respecteren, maar belanghebbenden zich er niet op kunnen beroepen voor de nationale rechter, die rechten al gauw een dode letter worden. ${ }^{5}$

Het Hof van Justitie besteedt de meeste overwegingen aan de beantwoording van het eerste deel van de tweede prejudiciële vraag, of het eerst in de administratieve bezwaarfase horen kan worden begrepen onder het beginsel van eerbiediging van de rechten van de verdediging. Dat is opvallend. Advocaat-generaal Van Hilten stelt in haar conclusie bij de verwijzingsuitspraak van de

\footnotetext{
Sopropé, punten 30-31.

Arrest Kamino, punten 34-35.

Conclusie A-G Wathelet van 25 februari 2014
}

Hoge Raad dat eigenlijk niet ter discussie staat dat gehoord moet worden voordat een bezwarend besluit wordt genomen. ${ }^{6}$ Toch lijkt het erop dat het Hof van Justitie het horen in bezwaar hier fiatteert. In punt 49 herinnert het Hof van Justitie aan het doel van de hoorplicht. De bevoegde autoriteit wordt in staat gesteld naar behoren rekening te houden met alle voor het besluit relevante elementen. Daarnaast beoogt de regel dat de adressaat van een bezwarend besluit gelegenheid wordt gegeven zijn opmerkingen kenbaar te maken voordat dit besluit wordt genomen om de effectieve bescherming van de betrokken persoon of onderneming te verzekeren, door deze in staat te stellen om een vergissing te corrigeren of individuele omstandigheden aan te voeren die relevant zijn voor het uiteindelijk te nemen besluit. ${ }^{7}$ Iedereen moet daarom in de gelegenheid worden gesteld naar behoren en daadwerkelijk zijn standpunt kenbaar te maken in het kader van een administratieve procedure vóórdat een besluit wordt genomen dat zijn belangen op nadelige wijze kan beïnvloeden. Gebeurt dat niet, dan is dat een beperking van het recht te worden gehoord. ${ }^{8}$

Dat betekent niet zonder meer dat het beginsel van eerbiediging van de rechten van de verdediging is geschonden. Het recht gehoord te worden is niet absoluut en kan worden beperkt, mits de beperking werkelijk beantwoordt aan de doeleinden van algemeen belang die met de betrokken maatregel worden nagestreefd, en, het nagestreefde doel in aanmerking genomen, niet zijn te beschouwen als een onevenredige en onduldbare ingreep, waardoor de gewaarborgde rechten in hun kern worden aangetast. ${ }^{9}$ Is het Nederlandse systeem, waarbij soms pas wordt gehoord in de bezwaarfase, een dergelijke gerechtvaardigde beperking? De argumenten die de Nederlandse regering naar voren brengt worden door het Hof van Justitie afgeserveerd, maar elders in het arrest komt het Hof van Justitie de Nederlandse regering te hulp en formuleert het zelf een algemeen belang dat gediend is bij het niet horen voorafgaand aan de UTB's: 'Het algemeen belang van de Unie en met name het belang dat zij heeft bij een snelle inning van haar eigen middelen, vereisen dat controles onverwijld en doeltreffend kunnen worden uitgevoerd.' ${ }^{10}$ Daarmee is een doel van algemeen belang gegeven. Blijft over de vraag of de beperking niet onevenredig is en het recht gehoord te worden niet in de kern aantast.

In punt 55 overweegt het Hof van Justitie dat uit zijn rechtspraak volgt dat het achteraf horen van geadresseerden in het kader van een beroep tegen een afwijzend besluit, onder bepaalde voorwaarden de eerbiediging kan verzekeren van het recht om te worden gehoord. ${ }^{11}$

Conclusie A-G Van Hilten 22 februari 2013, ECLI:NL:PHR:2013: BR0666, par. 6.18 .

Kamino, punt 38.

Punt 41.

Punt 42.

10. Punt 54

11. De term 'afwijzend besluit' lijkt een eigenaardigheid die in de Nederlandse tekst is geslopen. Bedoeld is een bezwarend besluit. De Engelse versie spreekt althans gewoon van een 'adverse decision,' de Duitse van een 'nachteilige Entscheidung.' 
Het verklaart die jurisprudentie analoog van toepassing op deze zaak. Of aan die voorwaarden voldaan is, laat het Hof van Justitie ter beoordeling aan de verwijzende rechter. Het identificeert wel een aantal factoren die van belang zijn bij het beantwoorden van die vraag. Dat in een later stadium, namelijk tijdens de bezwaarprocedure, wel gehoord wordt, is verzekerd in de Awb. Dat dit bezwaar niet automatisch de betalingsverplichting schorst, doet de inbreuk op de rechten van de verdediging weliswaar zwaarder wegen, maar is - gezien het doel van de beperking - niet noodzakelijk een probleem. Daarbij is van belang dat wanneer om schorsing verzocht wordt, dat verzoek over het algemeen wordt toegekend, en dat dit ook mede verzekerd wordt door een ministeriële circulaire. Het Hof van Justitie laat het aan de Hoge Raad om te beoordelen of deze circulaire voldoende verzekert dat adressaten van een uitnodiging tot betaling die niet vooraf worden gehoord daadwerkelijk de opschorting van de uitvoering kunnen verkrijgen. Opschorting moet in ieder geval mogelijk zijn wanneer er redenen zijn om aan de overeenstemming van de aangevochten beschikking met de douanewetgeving te twijfelen, of indien de belanghebbende onherstelbare schade dreigt te lijden.

Het Hof van Justitie beslist uiteindelijk in punt 73: Het niet-horen kan schending van het beginsel van de rechten van de verdediging opleveren, wanneer zou blijken dat adressaten de betalingsverplichting niet opgeschort kunnen krijgen. Het Hof van Justitie wijkt hiermee af van de conclusie van advocaat-generaal Wathelet, die meende dat wel een schending van de rechten van de verdediging aan de orde was maar die adviseerde dat deze schending zonder rechtsgevolg zou blijven als het tijdig horen niet tot een andere uitkomst zou kunnen hebben geleid.

Wordt de betalingsverplichting wél opgeschort, dan hebben we dus te maken met een gerechtvaardigde beperking, en is er geen sprake van een schending van de rechten van de verdediging. In dat geval wordt aan de laatste twee vragen niet eens toegekomen. Omdat het Hof van Justitie de beantwoording van de vraag of de betalingsverplichting inderdaad op verzoek van de belanghebbende opgeschort wordt aan de Hoge Raad overlaat, blijven deze antwoorden toch relevant. Het Hof van Justitie behandelt ze gezamenlijk. Het bevestigt het beginsel van de procedurele autonomie: het verbinden van gevolgen aan schending van de rechten van de verdediging is, bij afwezigheid van een Unierechtelijke regeling, aan de lidstaten. Daarbij gelden wel het gelijkwaardigheidsbeginsel en het doeltreffendheidsbeginsel. Het Hof van Justitie concludeert dan dat een schending pas leidt tot nietigverklaring van het na afloop van de betrokken administratieve procedure genomen besluit, wanneer deze procedure zonder deze onregelmatigheid een andere afloop zou kunnen hebben gehad. ${ }^{12}$

12. Overweging 82 .

\section{De aanleiding voor de vragen van de Hoge Raad}

Met zijn prejudiciële vragen probeert de Hoge Raad duidelijkheid te scheppen in de situatie die is ontstaan na het Sopropé-arrest waarin het Hof van Justitie oordeelde dat de rechten van de verdediging ook van toepassing zijn op het horen in douanezaken. De controverse over de verenigbaarheid van afdeling 4.1 .2 van de Awb met het Unierechtelijke verdedigingsbeginsel is echter al ouder. Het is vaste jurisprudentie dat de lidstaten bij de tenuitvoerlegging van Europees recht het beginsel van de rechten van de verdediging moeten respecteren. Het is immers een van de algemene beginselen van het Unierecht. Uit het beginsel vloeit onder meer een hoorplicht voort: geadresseerden moeten gehoord worden voordat een voor hen belastend besluit wordt genomen. ${ }^{13}$ In veel gevallen vereist ook het Nederlandse recht dat belanghebbenden gehoord worden alvorens een bestuursorgaan een beschikking neemt waartegen zij naar verwachting bedenkingen zullen hebben. Horen alvorens een besluit te nemen is verplicht als aan de cumulatieve voorwaarden uit artikel 4:8 lid $1 \mathrm{Awb}$ is voldaan. Op deze verplichting kan het bestuursorgaan krachtens artikel 4:12 lid 1 Awb een uitzondering maken wat betreft beschikkingen die strekken tot het vaststellen van een financiële verplichting of aanspraak, wanneer althans tegen de beschikking bezwaar of administratief beroep openstaat en de nadelige gevolgen van de beschikking na bezwaar of administratief beroep volledig ongedaan kunnen worden gemaakt. Vooraf horen is dus niet altijd verplicht. Maar ook wanneer ten onrechte niet wordt gehoord, zijn de gevolgen beperkt. De rechter zal vaak de rechtsgevolgen van het besluit in stand kunnen laten indien aannemelijk is dat de belanghebbende daardoor niet is benadeeld, aldus artikel 6:22 Awb. Omdat in de bezwaarprocedure in beginsel wel gehoord wordt, zal dat maar zelden het geval zijn. Heeft het bestuursorgaan belangrijke informatie gemist door niet te horen voordat het primaire besluit werd genomen, dan kan het dat gedurende de bezwaarprocedure gemakkelijk corrigeren. In het Europese recht is het uitgangspunt echter dat gehoord moet worden voordat een bezwarend besluit wordt genomen. ${ }^{14}$ De voorwaardelijke hoorplicht van artikel 4:8 Awb is beperkter, en de uitzondering van artikel 4:12 Awb is ook moeilijk te verenigen met het Europese recht. ${ }^{15}$ Toch is niet op voorhand duidelijk of en in hoeverre er strijd is met het Unierecht. Voorstanders van de regeling in de Awb wijzen erop dat het recht gehoord te worden niet absoluut is. Daarnaast wordt wel betoogd dat het bestuurlijke besluitvormingsproces als één geheel gezien moet wor-

13. Zie uitgebreid R.J.G.M. Widdershoven, M.J.M. Verhoeven e.a., De Europese agenda van de Awb, Den Haag: Boom Juridische uitgevers 2007, p. 79.

14. Zie bijvoorbeeld HvJ EG 24 oktober 1996, zaak C-32/95 P, CommissieLisrestal, ECLI:EU:C:1996:402.

15. Widdershoven, Verhoeven e.a. 2007, p. 82. Het staat bestuursorganen overigens vrij wel te horen, ook al verplicht de Awb daar niet toe. 
den, en dat horen in de bezwaarfase voldoende is om de eerbiediging van de rechten van de verdediging te garanderen. ${ }^{16}$ Bovendien is onduidelijk welke consequenties verbonden moeten worden aan het schenden van de rechten van de verdediging, en onder welke voorwaarden aan een dergelijk gebrek voorbij kan worden gegaan. ${ }^{17}$

De kwestie werd op scherp gesteld toen het Hof van Justitie zich uitsprak over de rechten van de verdediging in douanezaken in het Sopropé-arrest, waarin de interpretatie van het recht gehoord te worden aan de orde kwam. In die zaak hadden de Portugese douaneautoriteiten de expediteur wel gehoord, maar die vond dat hij onvoldoende tijd had gekregen om zijn standpunt goed voor het voetlicht te brengen. In dat arrest oordeelde het Hof van Justitie dat ook in douanezaken de rechten van de verdediging geëerbiedigd moesten worden. ${ }^{18}$ Het liet het aan de nationale rechter om te bepalen of de geboden termijn belanghebbenden daadwerkelijk in staat stelde te reageren op de door het bestuursorgaan gestelde punten. ${ }^{19}$ Uit het Sopropé-arerst zijn in Nederland vergaande conclusies getrokken, zowel voor het douanerecht als daarbuiten. ${ }^{20}$ Zowel de Rechtbank Haarlem als het Hof Amsterdam stelde zich op het standpunt dat de uitreiking van UTB's zonder vooraf te horen in strijd is met het Europese recht, hoewel de douane volhield dat aan de rechten van de verdediging tegemoet is gekomen zo lang in bezwaar gehoord wordt. ${ }^{21}$ In nieuwe zaken maakte de douane naar aanleiding van Sopropé voor de zekerheid toch het voornemen een UTB uit te reiken van tevoren aan belanghebbenden bekend. ${ }^{22}$ Een consistente lijn ten aanzien van de consequenties van het niet horen ontbrak. Soms werden UTB's direct vernietigd wegens schendig van de rechten van de verdediging, ${ }^{23}$ soms ook werden ze in stand gelaten met het argument

16. K.P.H. van der Schoot, 'Arrest-Sopropé: enige nuanceringen,' WFR 2009/1432.

17. Conclusie A-G Van Hilten 22 februari 2013, ECLI:NL:PHR: 2013:BR0666, par. 7.1 e.v

18. Sopropé, punt 38.

19. Sopropé, punt 47

20. B.J.B. Boersma, 'Arrest-Sopropé: handelswijze Nederlandse Douane moet drastisch anders,' WFR 2009/662; D. Wijkhuizen, O wee! Sopropé!, Europese Fiscale Studies, 2011, <www.europesefiscalestudies.nl/ upload/Dinske \%20Wijkhuizen \%20-\%200\%20wee! \%20Soprope!.pdf>, p. 3. Ook in andere rechtsgebieden deed de uitspraak van het Hof van Justitie veel stof opwaaien, met name in het vreemdelingenrecht. Daar stelde de Afdeling in 2013 ook prejudiciële vragen, met verzoek de spoedprocedure toe te passen. Zie ook G.J. van Midden, 'Over de gevolgen van Sopropé buiten het belastingrecht: De reikwijdte van Sopropé voorgelegd aan het Hof van Justitie EU,' JutD 2013-22, p. 10-13. Zie ook bijvoorbeeld ABRvS 12 december 2012, ECLI:NL:RVS: 2012:BY7400 (een vreemdelingenzaak).

21. Met het oog op Sopropé is dat geen sterk verhaal: het CDW verplicht namelijk ook al tot bezwaar en dat ontsloeg de Portugese douaneautoriteit niet van de verplichting ook in de fase voorafgaand aan het besluit de rechten van de verdediging te respecteren (zie de conclusie van A-G Van Hilten, par. 6.12). Zie ook Boersma in zijn naschrift bij Van der Schoot 2009.

22. Wijkhuizen 2011, p. 21.

23. De enige juiste oplossing, aldus Boersma 2009. Zie bijv. Rb. Haarlem 12 maart 2009, ECLI:NL:RBHAA:2009:BH9755; Rb. Haarlem 3 april 2009, ECLI:NL:RBHAA:2009:B19735, AB 2009, 326, m.nt. Widdershoven; Hof Amsterdam 21 april 2011, ECLI:NL:GHAMS:2011:BQ2794. dat belanghebbenden geen nadeel hadden ondervonden van het niet horen. ${ }^{24}$

De verwarring die is ontstaan is begrijpelijk. Het Sopropé-arrest liet een aantal vragen onbeantwoord. Ten eerste ging het Hof van Justitie in Sopropé niet expliciet in op de vraag of horen verplicht was. Dat stond ook niet ter discussie, er was in die zaak namelijk wel gehoord. De vraag was of de belanghebbende wel voldoende tijd had gekregen om daadwerkelijk gebruik te maken van dat hoorrecht. Het Hof van Justitie heeft meermalen duidelijk gemaakt dat het horen voorafgaand aan een belastend besluit deel uitmaakt van de rechten van de verdediging. ${ }^{25}$ Toch twijfelt de Hoge Raad. Daar zijn twee redenen voor. Ten eerste wijst advocaat-generaal Van Hilten er in haar conclusie bij de verwijzingsuitspraak op dat het Hof van Justitie weliswaar veelvuldig concludeert dat de rechten van de verdediging worden geschonden door niet te horen voorafgaand aan een besluit, maar dat het daarbij vaak gaat om besluiten waartegen geen bezwaar openstaat. ${ }^{26}$ Ten tweede heeft het Hof van Justitie bepaald dat de rechten van de verdediging niet absoluut zijn, maar dat een inbreuk daarop gerechtvaardigd kan zijn om redenen van algemeen belang. ${ }^{27}$ Het standpunt dat horen in bezwaar voldoende is, werd in de onderhavige zaak voor het Hof van Justitie verdedigd door de Nederlandse regering: doordat in bezwaar gehoord wordt, is er geen sprake van een aantasting in de kern van de rechten van de verdediging. ${ }^{28}$ Daarnaast was onduidelijk wat de consequenties zijn van een schending van de rechten van de verdediging. ${ }^{29}$ In Sopropé vroeg de verwijzende rechter daar niet naar en voor het overige lijkt het Hof van Justitie geen consequente lijn te hanteren. Soms leidt schending van de rechten van de verdediging zonder meer tot nietigverklaring van het besluit. ${ }^{30}$ In andere zaken stelt het Hof van Justitie zich milder op, en laat het het besluit in stand zolang de betrokkene geen nadeel heeft ondervonden van de schending. ${ }^{31}$ Overigens is het niet zo dat de belanghebbende moet aantonen dat een ander besluit zou zijn genomen wanneer wel was gehoord. Het is voldoende dat hij zich beter had kunnen verweren wanneer de onregelmatigheid niet was opgetreden. ${ }^{32}$ Waarin de

24. Hof Amsterdam 4 maart 2010, ECLI:NL:GHAMS:2010:BL6952

25. HvJ EG 24 oktober 1996, zaak C-32/95 P, Lisrestal/Commissie, ECLI:EU:C:1996:402; HvJ EG 29 juni 1994, zaak C-135/92, Fiskano, ECLI:EU:C:1994:267.

26. Par. 6.11.

27. HvJ EG 15 juni 2006, zaak C-28/05, Dokters, ECLI:EU:C:2006:408.

28. Punt 45.

29. Zie daarover het debat tussen Boersma en Van der Schoot, zie noot 2 supra en K.P.H. van der Schoot, 'Arrest-Sopropé: enige nuanceringen,' WFR 2009/1432.

30. HvJ EG 21 september 2000, zaak C-462/98 P, Mediocurso/Commissie, ECLI:EU:C:2000:480; HvJ EG 20 januari 2005, zaak C-300/03, Honeywell Aerospace GmbH, ECLI:EU:C:2005:43; HvJ EG 9 juli 2009, zaak C-511/06 P, Archer Daniels Midland, ECLI:EU:C:2009:433.

31. HvJ EG 10 juli 1980, zaak C-30/78, Distillers Company, ECLI:EU:C: 1980:186; HvJ EG 21 maart 1990, zaak C-142/87, België/Commissie, ECLI:EU:C:1990:125.

32. HvJ EG 2 oktober 2003, zaak C-194/99 P, Thyssen Stahl, ECLI:EU:C: 2003:527. 
verschillende cases zich onderscheiden, is onduidelijk. ${ }^{33}$ Reden dus om de zaak voor te leggen aan het Hof van Justitie.

\section{De consequenties van de uitspraak}

Voor de Nederlandse douane is deze uitspraak goed nieuws. Het blijkt dat te vergaande conclusies zijn getrokken uit Sopropé: het verdedigingsbeginsel is wel altijd van toepassing, maar daaruit volgt niet dat er altijd een verplichting is te horen voordat het initiële besluit wordt genomen. Juister is dus te zeggen dat Sopropé, wanneer er een recht gehoord te worden in de voorfase bestaat, criteria stelt waaraan dat recht dient te voldoen. Deze uitspraak werpt op zijn beurt licht op de voorwaarden waaronder men kan volstaan met horen in de bezwaarfase. Het lijkt erop dat aan die voorwaarden is voldaan bij het uitreiken van UTB's. De rechter kan die dus voortaan in stand laten: niet omdat schending van de hoorplicht niet tot vernietiging hoeft te leiden, maar omdat het beginsel van de rechten van de verdediging niet is geschonden. Desalniettemin lijkt de houdbaarheid van deze praktijk beperkt, want het CDW wordt gewijzigd. Het CDW bevat een verplichting te horen alvorens een ongunstige beschikking wordt getroffen. ${ }^{34}$ Verder is de regeling in de Awb hiermee nog niet gered. De uitzondering op de hoorplicht is in dit geval wel aanvaardbaar, maar dat lijkt vooral te komen door de kenmerken van het douanerecht. Artikel 4:12 van de Awb is ook buiten het douanerecht van toepassing. Of deze bepaling in alle gevallen verenigbaar is met het Unierecht is nog verre van beslist. De hoofdregel dat gehoord moet worden voordat een belastend besluit wordt genomen blijft in stand. Gebeurt dat niet, dan is er sprake van een inbreuk op de rechten van de verdediging. Een dergelijke inbreuk kan gerechtvaardigd zijn, mits zij een legitiem doel dient en het recht niet in de kern aantast. Het is niet evident dat voor alle besluiten die uitgezonderd worden in artikel 4:12 Awb een belang aanwezig is dat een inbreuk op de rechten van de verdediging rechtvaardigt. De regeling is primair opgenomen om te voorkomen dat de hoorplicht een te grote belasting zou opleveren voor bestuursorganen die grote aantallen beschikkingen nemen. ${ }^{35}$ Het Hof van Justitie kent in deze zaak een groot gewicht toe aan de voordelen die de inbreuk oplevert voor de eigen financiën van de

33. Conclusie A-G Van Hilten 22 februari 2013, ECLI:NL:PHR: 2013:BR0666; M. Lammers, De toepassing en gevolgen van het verdedigingsbeginsel, Europese Fiscale Studies, 2012, <www. europesefiscalestudies.nl/upload/12.\%20Marloes \%20Lammers \%20-

$\% 20$ Verhandeling.pdf> onderscheidt drie categorieën: nietigverklaring zonder meer, in stand laten zolang betrokkene geen nadeel heeft ondervonden, en afweging van de schending van de rechten van de verdediging tegen het belang dat gediend is bij instandhouding van het besluit.

34. Zie Conclusie A-G Van Hilten, par. 6.16.

35. Kamerstukken I/ 1988/89, 21 221, nr. 3, p. 104 (MvT) en Kamerstukken II 1993/94, 23 700, nr. 3, p. 99-100 (MvT).
Unie. Of puur nationale belangen als de efficiëntie van de besluitvormingsprocedure even gemakkelijk een dergelijke inbreuk rechtvaardigen, is daarmee dus nog niet duidelijk. De Nederlandse regering had aangevoerd dat vooraf horen niet verenigbaar is met de verplichte regels van boeking en inning uit het Douanewetboek. Als doel van de beperking poneert de regering administratieve vereenvoudiging en een efficiënt beheer van de procedure. Zij beroept zich ook op het feit dat het gaat om een zeer groot aantal uitnodigingen tot betaling, waarbij bovendien de termijn waarbinnen de uitnodiging tot betaling moet worden gedaan zeer kort is (twee dagen). ${ }^{36}$ Het Hof van Justitie gaat niet mee in deze redenering. De korte termijn kan verlengd worden, en bovendien moet de hoorplicht die bestaat in de rechtsbetrekking tussen de lidstaat en een belastingplichtige los worden gezien van de betrekking tussen de lidstaten en de Unie. ${ }^{37}$ Het Hof van Justitie komt wel zelf met een doel dat de beperking van de rechten van de verdediging rechtvaardigt: het algemeen belang van de Unie en met name het belang dat zij heeft bij een snelle inning van haar eigen middelen, hetgeen vereist dat controles onverwijld en doeltreffend kunnen worden uitgevoerd. ${ }^{38}$ Het Hof van Justitie stelt ook eisen aan de inrichting van de bezwaarprocedure. Of een bezwaar automatisch het besluit in eerste aanleg schorst, is een relevante factor bij de beoordeling of een beperking van het recht gehoord te worden gerechtvaardigd is. ${ }^{39}$ In Nederland heeft bezwaar in de regel geen schorsende werking, aldus artikel 6:16 Awb. Onder omstandigheden is dat te billijken, maar de belanghebbende moet wel op verzoek een schorsing kunnen verkrijgen als er reden is de twijfelen aan de inhoud van het primaire besluit, of indien hij onherstelbare schade dreigt te lijden. Zo niet, dan is alsnog sprake van een (ongerechtvaardigde) schending van de rechten van de verdediging. ${ }^{40}$ Dat het op het randje is, blijkt al uit de conclusie van de advocaat-generaal, die de bezwaarprocedure onvoldoende tegemoet vindt komen aan de belanghebbende en wel concludeert dat de rechten van de verdediging zijn geschonden.

Het praktisch belang daarvan is overigens niet groot, omdat ook aan een schending van de rechten van de verdediging geen vergaande rechtsgevolgen worden gehecht. Hoogstens loopt het bestuursorgaan door het schenden van dit beginsel het risico veroordeeld te worden in de proceskosten. Het vernietigen van een besluit op grond van het enkele feit dat niet gehoord is, zou zelfs afbreuk kunnen doen aan de nuttige werking van Europese regelgeving, en is dus geen optie meer voor de rechter. ${ }^{41}$ Eerder stelde de Afdeling in een vreemdelingenzaak al prejudiciële vragen over de consequenties van een schending van de rechten van de verdediging. ${ }^{42} \mathrm{De}$

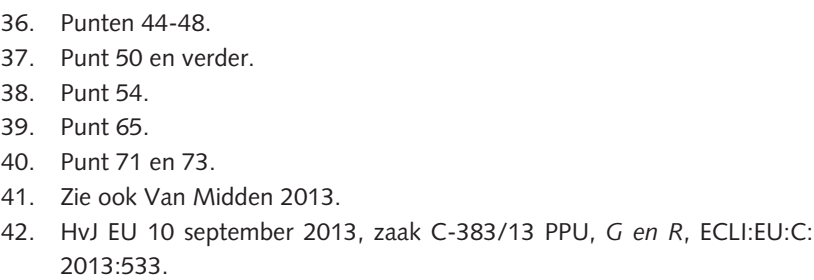


Afdeling wilde weten of schending van het algemene beginsel van de eerbiediging van de rechten van de verdediging bij het nemen van een besluit waarmee de inbewaringstelling van een vreemdeling wordt verlengd ertoe moet leiden dat die bewaring moet worden opgeheven. Dat blijkt niet het geval. Het Hof van Justitie herinnert aan zijn zogenoemde zachte lijn, waarin een dergelijke schending alleen leidt tot nietigverklaring van het bestreden besluit wanneer de procedure een andere afloop zou hebben gehad als die rechten wel waren geëerbiedigd. Enkel en alleen op grond van een dergelijke schending vernietigen hoeft dus niet. ${ }^{43}$ Sterker nog, het mag niet. Lidstaten zijn in beginsel vrij de consequenties te bepalen die worden verbonden aan een schending van procedurele rechten, maar die vrijheid is begrensd. Het Hof van Justitie vindt dat wanneer de inbewaringstelling wel terecht was, het nuttig effect van het EU-recht wordt ondergraven door de vreemdeling in vrijheid te stellen. De richtlijn maakt immers de verwijdering van elke illegaal verblijvende onderdaan van een derde land tot een prioriteit voor de lidstaten. ${ }^{44}$

Zouden de besluiten inderdaad vernietigd moeten worden, dan schieten belanghebbenden daar overigens weinig mee op: de douane kan na vernietiging door de rechter een nieuwe UTB uitreiken, mits ze binnen de wettelijke termijn blijft. De Hoge Raad bevestigde dat onlangs ook. ${ }^{45}$

Een belangrijke vraag over de rechten van de verdediging blijft ook met deze uitspraak onbeantwoord. De Hoge Raad herinnert eraan dat het verdedigingsbeginsel tot uitdrukking is gebracht in artikel 41 lid 2 van het Handvest van de Grondrechten van De Europese Unie. ${ }^{46}$ Het Hof van Justitie volstaat met de opmerking dat artikel 41 niet van toepassing is op deze zaken, die speelden voor de inwerkingtreding van het Handvest. Daarmee vermijdt het een kwestie die de Hoge Raad wel aanroerde in zijn verwijzingsuitspraak, maar niet expliciet voorlegde aan het Hof van Justitie: richt artikel 41 van het Handvest zich mede tot de lidstaten? Aanvankelijk leek dat wel zo, omdat het artikel verplichtingen codificeert die ook van toepassing waren op de lidstaten, althans wanneer zij Europees recht ten uitvoer leggen. ${ }^{47}$ Maar het Cicala-arrest van het Hof van Justitie zaaide twijfel. In een terzijde in die uitspraak overwoog het Hof van Justitie dat artikel 41 zich volgens zijn bewoordingen niet tot de lidstaten maar uitsluitend tot de instellingen en organen van de Unie richt. ${ }^{48}$ De Afdeling heeft naar aanleiding hiervan prejudiciële vragen gesteld, maar wacht nog steeds op antwoord. ${ }^{49}$

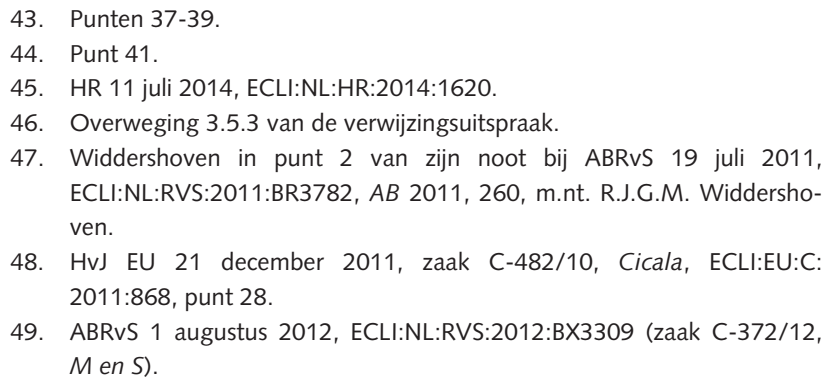

Inderdaad richt artikel 41 van het Handvest zich uitdrukkelijk tot de instellingen, organen en instanties van de Unie. Daaronder vallen niet de autoriteiten van de lidstaten. Artikel 51 van het Handvest bepaalt immers dat de bepalingen van het Handvest niet alleen bindend zijn voor de instellingen, organen en instanties van de Unie, maar ook voor de lidstaten, wanneer zij het recht van de Unie ten uitvoer brengen. Onder de instellingen, organen en instanties van de Unie die in artikel 41 van het Handvest expliciet genoemd worden, bevinden zich dus niet de autoriteiten van de lidstaten. Het Hof van Justitie lijkt in Cicala voor deze grammaticale interpretatie te kiezen. Toch laat die uitspraak wel wat ruimte. In Cicala ging het om een puur interne situatie, waar een beroep werd gedaan op de rechten van de verdediging. Het Hof van Justitie overweegt dat in een dergelijke puur interne situatie nationale regels niet opzij kunnen worden geschoven door het Europese recht. Met de nodige goede wil is de opmerking van het Hof van Justitie uit te leggen als een bevestiging van het feit dat artikel 41 van het Handvest zich niet richt tot de lidstaten wanneer zij geen uitvoering geven aan Europees recht. Advocaat-generaal Wathelet zet de deur wijd open voor deze interpretatie van Cicala. Volgens hem valt niet te betwisten dat artikel 41 van het Handvest ook door de lidstaten moet worden geëerbiedigd, overeenkomstig artikel 51 lid 1 van het Handvest. ${ }^{50}$ Of hij gelijk heeft, moeten we blijven afwachten. Hoe het ook zij, de verplichtingen die voortvloeien uit het beginsel van de eerbiediging van de rechten van de verdediging moet worden nagekomen. Alleen voor de toepasselijkheid van artikel 41 lid 1 is de kwestie van belang, omdat de daarin opgenomen rechten nog niet door het Hof van Justitie zijn erkend als algemene beginselen van Unierecht. ${ }^{51}$
50. Opinie A-G Wathelet, punt 34

51. Widdershoven in zijn noot bij Cicala, AB 2012, 254. 